\title{
Systematic review of antistaphylococcal antibiotic therapy in cystic fibrosis
}

\author{
Kevin McCaffery*, Richard E Olver, Margaret Franklin, Somnath Mukhopadhyay
}

\begin{abstract}
Background-The respiratory tract in patients with cystic fibrosis is frequently colonised with Staphylococcus aureus. There is great diversity of clinical practice in this area of cystic fibrosis. A systematic review was conducted to study the evidence relating antistaphylococcal therapy to clinical outcome in patients with cystic fibrosis.

Methods-A search strategy already evaluated for the study of the epidemiology of cystic fibrosis clinical trials was used. This yielded 3188 references from which 13 clinical trials of antistaphylococcal therapy were identified.

Results-Substantial heterogeneity was observed between trials. In the 13 clinical trials a total of 19 antibiotics were used to assess a wide variety of outcome measures (11 clinical, six laboratory). Both intermittent and continuous treatment strategies were used. Sputum clearance of $S$ aureus was more frequently achieved than any other beneficial outcome. A beneficial effect on pulmonary function was rarely measured or observed. Although five randomised clinical trials were identified, the extent of heterogeneity precluded the use of meta-analysis for further synthesis of information.

Conclusions-Antistaphylococcal treatment achieves sputum clearance of $S$ aureus in patients with cystic fibrosis. Prophylactic antistaphylococcal treatment in young children with cystic fibrosis is likely to be of clinical benefit. It remains to be determined whether the use of "prophylactic" versus "intermittent" antistaphylococcal therapy in cystic fibrosis is associated with improved lung function and/or chest radiographic scores, an increase in bacterial resistance, or earlier acquisition of Pseudomonas aeruginosa. A large randomised clinical trial lasting approximately two years is urgently required to address this problem.

(Thorax 1999;54:380-383)
\end{abstract}

Keywords: cystic fibrosis; Staphylococcus aureus; systematic review

Staphylococcus aureus frequently colonises the respiratory tract of patients with cystic fibrosis and is often treated intermittently or continuously with different antistaphylococcal antibiotics. ${ }^{1-3}$ The benefits of such treatment in cystic fibrosis appear to vary from study to study, leading to a lack of evidence based clinical guidelines for the management of this common and potentially important problem; current clinical practice is thus greatly divergent. ${ }^{4}$ This lack of a rational basis for clinical strategy may result, as in other areas of management in cystic fibrosis, from insufficient patient data collected through small descriptive or incompletely randomised clinical trials. ${ }^{56}$ Systematic reviewing is effective in pooling together relatively limited clinical data to answer questions of clinical interest in cystic fibrosis, thus facilitating clinical decision making and helping the design of future clinical trials. ${ }^{7}$ Here we systematically review the evidence for antistaphylococcal therapy in cystic fibrosis using a search strategy $^{89}$ that has been evaluated in cystic fibrosis, ${ }^{7}$ with the aim of providing a scientific basis for the development of treatment guidelines and the listing of currently unanswered questions to allow well designed randomised clinical trials to be performed in this area in the future.

\section{Methods}

MEDLINE

Publications in the years 1966-1995 inclusive were identified using a search strategy developed by the UK Cochrane Centre for optimal recall of randomised clinical trials ${ }^{89}$ with modifications to allow its use with the Medline database on CD ROM that we have described previously. $^{7}$

\section{EMBASE AND MEDLINE EXPRESS}

Embase and Medline Express searches were performed in combination for the years 19661995 inclusive according to the following protocol, using the keywords "cystic fibrosis" and "Staphylococcus aureus":

(1) explode "cystic-fibrosis"/all subheadings;

(2) explode "staphylococcal-infections"/all subheadings;

(3) nos 1 and 2 combined;

(4) explode "staphylococcal-infections"/all subheadings;

(5) explode "Staphylococcus-aureus"/all subheadings;

(6) nos 4 and 5 combined;

(7) nos 1 and 6 combined. 
Table 1 Clinical heterogeneity: characteristics of clinical trials of antistaphylococcal treatment in cystic fibrosis

\begin{tabular}{|c|c|c|c|c|c|}
\hline First author & Study design & $\begin{array}{l}\text { Subjects } \\
(n)\end{array}$ & Antibiotic or antibiotic combinations used & Clinical strategy & $\begin{array}{l}\text { Follow up } \\
\text { period }\end{array}$ \\
\hline Wright $^{2}$ (ME,B) & NRNC & 18 & $\begin{array}{l}\text { Fusidic acid + lincomycin, chloramphenicol, cloxacillin, penicillin } \mathrm{V} \text {, } \\
\text { novobiocin, ampicillin }\end{array}$ & $\begin{array}{l}\text { Eradication then } \\
\text { continuous }\end{array}$ & $5-19 \mathrm{~m}$ \\
\hline Loening-Bauke $^{1}(\mathrm{M}, \mathrm{B})$ & RCTC & 17 & $\begin{array}{l}\text { Cephalexin, ampicillin, erythromycin, dicloxacillin, penicillin, } \\
\text { carbenicillin, gentamicin }\end{array}$ & Continuous & $2 \mathrm{y}$ \\
\hline Brown $^{12}(\mathrm{ME}, \mathrm{B})$ & NRNC & & $\begin{array}{l}\text { Cloxacillin, flucloxacillin, erythromycin, chloramphenicol, } \\
\text { lincomycin, clindamycin, fusidic acid, cotrimoxazole }\end{array}$ & Intermittent & $4.5 \mathrm{y}$ \\
\hline Shapera $^{13}(\mathrm{ME}, \mathrm{B})$ & $\mathrm{RNC}$ & 29 & Clindamycin (oral) versus clindamycin (im/iv) + oral clindamycin & Eradication & $3-6 \mathrm{~m}$ \\
\hline Szaff $^{14}(M E, B)$ & NRNC & 191 & $\begin{array}{l}\text { Fusidic acid + oxacillin, dicloxacillin, fusidic acid + rifampicin, } \\
\text { lincomycin, penicillin V, methicillin (inhaled) }\end{array}$ & Intermittent & $14 \mathrm{y}$ \\
\hline Schlesinger ${ }^{15}(\mathrm{~B})$ & RCT & 28 & Trimethoprim, sulphamethoxazole, cefadroxil, dicloxacillin & $\begin{array}{l}\text { Continuous versus } \\
\text { intermittent }\end{array}$ & $1 \mathrm{y}$ \\
\hline Kerrebijn $^{16}(\mathrm{~B})$ & NRCT & 95 & Not mentioned & $\begin{array}{l}\text { Continuous versus } \\
\text { intermittent }\end{array}$ & $5 \mathrm{y}$ \\
\hline Harrison $^{17}(\mathrm{ME}, \mathrm{M}, \mathrm{B})$ & RCT & 21 & Cephalexin vs dicloxacillin & Continuous & $2 \mathrm{~m}$ \\
\hline Jensen $^{18}(\mathrm{ME})$ & NRNC & 243 & $\begin{array}{l}\text { Dicloxacillin, fusidic acid, flucloxacillin, penicillin V, erythromycin, } \\
\text { rifampicin, clindamycin + fusidic acid }\end{array}$ & Intermittent & $2 \mathrm{y}$ \\
\hline Ballestero $^{19}$ (ME,EM) & NRNC & 60 & $\begin{array}{l}\text { Cefuroxime (inhaled), ciprofloxacin, cotrimoxazole, rifampicin, } \\
\text { macrolide, amoxycillin + clavulanic acid }\end{array}$ & Intermittent & $13 \mathrm{~m}$ \\
\hline Feigelson $^{20}(\mathrm{EM})$ & NRNC & 80 & Fusidic acid & Intermittent & $15 \mathrm{y}$ \\
\hline Beardsmore $^{11}(\mathrm{M})$ & RCT & 42 & $\begin{array}{l}\text { Flucloxacillin, cloxacillin, ampicillin, amoxycillin ( } \pm \text { clavulanic acid), } \\
\text { penicillin } \mathrm{V} \text {, erythromycin, cotrimoxazole, cephalosporin, } \\
\text { ciprofloxacin }\end{array}$ & $\begin{array}{l}\text { Continuous versus } \\
\text { intermittent }\end{array}$ & $1 \mathrm{y}$ \\
\hline Weaver $^{3}$ (ME,M,EM,B) & RCT & 38 & $\begin{array}{l}\text { Flucloxacillin, cloxacillin, ampicillin, amoxycillin ( } \pm \text { clavulanic acid), } \\
\text { penicillin V, erythromycin, cotrimoxazole, cephalosporin, } \\
\text { ciprofloxacin }\end{array}$ & $\begin{array}{l}\text { Continuous versus } \\
\text { intermittent }\end{array}$ & $2 \mathrm{y}$ \\
\hline
\end{tabular}

At least 19 different drugs were used over 13 studies, demonstrating extreme heterogeneity between trials.

$\mathrm{M}=$ Medline $\mathrm{ME}=$ Medline Express; $\mathrm{EM}=$ Embase $; \mathrm{B}=$ bibliography search RCT = randomised controlled trial; $\mathrm{NRNC}=$ non-randomised non-controlled, RNC $=$ randomised non-controlled, RCTC $=$ randomised controlled trial (crossover).

Table 2 Outcome measures addressed in randomised controlled trials assessing antistaphylococcal treatment

\begin{tabular}{|c|c|c|c|c|c|c|c|c|c|c|c|}
\hline Study & $P F T$ & $\begin{array}{l}\text { Chest } \\
\text { radiography } \\
\text { score }\end{array}$ & $\begin{array}{l}\text { Clearance of } S \\
\text { aureus from } \\
\text { sputum }\end{array}$ & $\begin{array}{l}\text { Cough } \\
\text { frequency }\end{array}$ & $\begin{array}{l}\text { Respiratory } \\
\text { exacerbations }\end{array}$ & $\begin{array}{l}\text { Antibiotic } \\
\text { courses }\end{array}$ & $E S R$ & $\operatorname{Ig} G$ & Weight & Height & $\begin{array}{l}\text { Hospital } \\
\text { admissions }\end{array}$ \\
\hline Schlesinger & 0 & 0 & + & 0 & 0 & 0 & + & + & + & 0 & 0 \\
\hline Weaver & 0 & $x$ & + & + & 0 & + & 0 & 0 & $x$ & $\times$ & + \\
\hline Beardsmore & $\times$ & 0 & 0 & 0 & 0 & 0 & 0 & 0 & 0 & 0 & 0 \\
\hline Harrison & 0 & 0 & + & $x$ & $x$ & 0 & 0 & 0 & $x$ & 0 & 0 \\
\hline
\end{tabular}

Antistaphylococcal therapy increases sputum clearance of $S$ aureus. Of the four studies listed above, those by Weaver and Beardsmore report different outcomes on the same population. While the first three trials did not report any side effects, Harrison et al reported possible earlier acquisition of Pseudomonas aeruginosa or conversion to mucoid strains with antistaphylococcal therapy.

$\mathrm{PFT}=$ pulmonary function tests; ESR = erythrocyte sedimentation rate; IgG = serum immunoglobulin $\mathrm{G}$ levels; + = positive outcome; $\times=$ difference not observed, $0=$ outcome not addressed.

Table 3 Outcome measures addressed in non-randomised clinical trials assessing continuous and intermittent administration of antistaphylococcal antibiotic treatment

\begin{tabular}{|c|c|c|c|c|c|c|c|c|c|c|c|}
\hline Study & PFT & $\begin{array}{l}\text { Chest } \\
\text { radiography } \\
\text { score }\end{array}$ & $\begin{array}{l}\text { Clearance of } \\
\text { S aureus from } \\
\text { sputum }\end{array}$ & $\begin{array}{l}\text { Cough } \\
\text { frequency }\end{array}$ & $\begin{array}{l}\text { Respiratory } \\
\text { exacerbations }\end{array}$ & $\begin{array}{l}\text { Antibiotic } \\
\text { courses }\end{array}$ & Weight & Height & $\begin{array}{l}\text { Clinical } \\
\text { score }\end{array}$ & $\begin{array}{l}\text { Side } \\
\text { effectst }\end{array}$ & $\begin{array}{l}\text { Bacterial } \\
\text { resistance }\end{array}$ \\
\hline \multicolumn{12}{|c|}{ Continuous administration } \\
\hline Loening-Bauke* & + & 0 & + & 0 & + & + & + & 0 & + & - & 0 \\
\hline Kerrebijn & 0 & $x$ & 0 & $x$ & + & 0 & $x$ & $x$ & 0 & 0 & 0 \\
\hline Wright & 0 & 0 & + & + & 0 & 0 & + & 0 & 0 & - & - \\
\hline Ballestero & 0 & 0 & 0 & 0 & 0 & 0 & 0 & 0 & 0 & 0 & - \\
\hline \multicolumn{12}{|c|}{ Intermittent administration } \\
\hline Brown & 0 & 0 & + & 0 & 0 & 0 & 0 & 0 & 0 & 0 & 0 \\
\hline Shapera & 0 & 0 & + & 0 & 0 & 0 & 0 & 0 & 0 & - & 0 \\
\hline Szaff \& Hoiby & 0 & 0 & + & 0 & 0 & $x$ & 0 & 0 & 0 & - & + \\
\hline Jensen & 0 & 0 & 0 & 0 & 0 & + & 0 & 0 & 0 & 0 & + \\
\hline Feigelson & 0 & 0 & + & 0 & 0 & 0 & 0 & 0 & 0 & - & + \\
\hline
\end{tabular}

Continuous antistaphylococcal treatment helps the clearance of $S$ aureus from the sputum but could lead to increased bacterial resistance while intermittent antistaphylococcal treatment helps the clearance of $S$ aureus from the sputum and may reduce the risk of increasing bacterial resistance. PFT $=$ pulmonary function tests; + $=$ positive outcome; $x=$ difference not observed; $-=$ negative outcome; $0=$ outcome not addressed. "Side effects" refers to direct drug related side effects, while reports of increased bacterial resistance as a side effect is recorded in the following column.

*The study by Loening-Bauke is a randomised clinical trial in which the patients acted as their own controls.

†Loening-Bauke observed superficial candidiasis and altered liver function tests (LFTs), Wright observed possible early acquisition of Pseudomonas aeruginosa or conversion to mucoid strains with antistaphylococcal treatment, minor gastrointestinal side effects, rash and altered LFTs, Shapera observed pain or burning at injection site, rash and minor gastrointestinal side effects, Szaff and Hoiby observed penicillin allergy and minor gastrointestinal side effects, and Feigelson observed minor gastrointestinal side effects only. 
HAND SEARCH

The bibliographies of all papers identified by the above two search strategies were studied.

LETTERS TO PHYSICIANS

Letters were sent to all cystic fibrosis physicians in the UK (with help from the Cystic Fibrosis Trust, UK) requesting information on studies being carried out in these patients.

BIBLIOGRAPHIES

Bibliographies of all relevant review articles (identified with the help of the above search strategies) were also studied.

\section{Results}

The search strategies yielded a total of 3188 references which were manually searched. One additional clinical trial protocol was identified at the time of peer review of this paper; however, although the trial protocol for this proposed randomised study has been published, ${ }^{10}$ the results were not obtained. Thirteen clinical trials on antistaphylococcal treatment in cystic fibrosis were identified. Medline Express was most efficient (8/13, $62 \%$ ), and the manual bibliography search identified two of the 13 studies (including one randomised controlled trial) not picked up by searching any of the three data bases. The Cystic Fibrosis Trust (UK) mailing list was used to inform all cystic fibrosis physicians in the UK of this study; four replies were received and no additional clinical data were identified. The principal characteristics of the clinical trials are listed in table 1.

Five studies on antistaphylococcal treatment were adequately randomised and controlled (table 1). Two examined different end points in the same population, ${ }^{311}$ and another ${ }^{1}$ used a crossover design with patients acting as their own controls over time and thus was very different in design from the other randomised controlled trials (it was therefore omitted from table 2 and is included in table 3 ). In the three studies potentially suitable for inclusion in a meta-analysis there was a large variation in clinical outcomes assessed, with weight and clearance of $S$ aureus from the sputum being the only outcomes common to all three studies (table 2). As there are potential dangers of interpretation associated with the use of metaanalysis in the context of such interstudy variability, it was felt to be more appropriate to present a qualitative analysis (in tabular form) of the outcome measures assessed by randomised controlled trials (table 2). Table 3 presents a qualitative analysis of the results of non-randomised clinical trials; for ease of interpretation trials assessing continuous (long term) antistaphylococcal antibiotic administration and those assessing intermittent antistaphylococcal antibiotic administration have been listed separately.

\section{Discussion}

Although quantitative synthesis of the currently available data on the clinical response to antistaphylococcal treatment in cystic fibrosis is precluded by trial heterogeneity, our system- atic review supports the hypothesis that antistaphylococcal treatment in cystic fibrosis achieves increased sputum clearance of $S$ aureus. The randomised controlled trials reported by Weaver et $a l^{\beta}$ and Beardsmore et $a l^{11}$ compared the clinical benefit of prophylactic flucloxacillin with the intermittent use of a heterogeneous group of antibiotics (with a varying effect on $S$ aureus). Despite this shortcoming, these two trials (which have different outcomes for the same population) effectively addressed the question of possible benefit from long term oral flucloxacillin. The two studies demonstrated increased clearance of $S$ aureus from respiratory secretions with "prophylactic" flucloxacillin (compared with intermittent use of heterogeneous antibiotics) and correlated this increase with improved clinical (reduced cough frequency and hospital admissions) and pharmacoeconomic (reduced antibiotic courses) outcomes, but failed to show an associated improvement in lung function. ${ }^{311}$ The results of the trial by Schlesinger et $a l,{ }^{15}$ using multiple antibiotics with broad spectrum antibacterial activity beyond that on $S$ aureus for both limbs of the trial, are more difficult to interpret, while the randomised trial of Harrison et $a l^{17}$ had a short follow up period and consequently showed no clinical benefit (table 2).

Of the three randomised controlled trials listed in table 2, only that by Weaver et $a l^{\beta}$ showed a significant difference in sputum clearance of $S$ aureus between continuous and intermittent antistaphylococcal therapy (17/20 versus 6/18 subjects, respectively, $\mathrm{p}<0.01)$. Schlesinger ${ }^{15}$ addressed the same question but her numbers were small (sputum clearance of $S$ aureus in both subjects receiving continuous treatment compared with two of seven with intermittent treatment). Although the third trial by Harrison ${ }^{17}$ again supported the hypothesis that antistaphylococcal therapy clears sputum $S$ aureus in cystic fibrosis (table 2), the paper addressed a different question in this context, comparing clearance of $S$ aureus with cephalexin (7/7 subjects) and dicloxacillin (4/6 subjects) when administered continuously orally for two months; both drugs appeared to be effective. Sputum clearance of $S$ aureus was again consistently improved with staphylococcus directed treatment in all nine non-randomised clinical trials that studied this outcome.

Beyond the above, however, there is limited evidence of clinical or pulmonary function improvement with antistaphylococcal therapy. Cough frequency, weight, frequency of respiratory exacerbations, hospital admissions, and antibiotic courses were the most common clinical outcome measures used. Colonisation of the sputum with $S$ aureus is of particular importance in young children with cystic fibrosis (11 of the 13 trials were on children aged five years or under) where measurement of pulmonary function is difficult and complicated. This is likely to account for the infrequent use of pulmonary function testing as an outcome measure (two of 13 trials), in contrast to the evaluation of nebulised antipseudomonal antibiotic therapy where pulmonary function testing represents an 
important outcome measure for most randomised controlled trials. ${ }^{7}$

While all nine studies that addressed the clearance of $S$ aureus from sputum showed evidence of benefit, only in two studies (both randomised controlled trials with follow up of one year or more) was there a beneficial effect on weight, and one study (a randomised controlled trial with crossover design and follow up of two years) demonstrated a beneficial effect on pulmonary function. It follows that, when designing future studies in this field, eradication of sputum $S$ aureus could act as an early and sensitive end point for evaluation, while the possibility of changes in weight, height, and pulmonary function would need to be studied in large populations of randomised subjects over a much longer time scale.

Finally, there is considerable diversity in clinical trial design, choice of outcome measures, antibiotics, and routes of administration that have been used to address the question of antistaphylococcal antibiotic efficacy in cystic fibrosis. Even if flucloxacillin, cloxacillin and dicloxacillin are considered as a single drug, as many as 19 different pharmaceutical approaches have used 11 clinical and six laboratory outcome measures in 13 clinical trials. This heterogeneity of clinical trials makes it more difficult to compare or synthesise clinical information from different studies. This systematic review has, however, identified our current state of knowledge and provides a framework for the design of future randomised controlled trials in this area. It is important to take this review forward as a multicentre randomised controlled trial to determine whether the use of "prophylactic" versus "intermittent" antistaphylococcal treatment in cystic fibrosis is associated with (a) improved lung function and/or chest radiographic scores, (b) an increase in bacterial resistance, or (c) earlier acquisition of Pseudomonas aeruginosa.

We would like to acknowledge the help received from Anna Crighton (Child Health, Dundee, supported by Tenovus, Scotland), Hoechst Marion Roussel (UK), the CF Trust (UK), and Simon Ogston (Epidemiology and Public Health, Dundee).
1 Loening-Bauke VA, Mischler E, Myers MG. A placebocontrolled trial of cephalexin therapy in the ambulatory management of patients with cystic fibrosis. $\mathcal{F}$ Pediatr 1979;95:630-7.

2 Wright GLT, Harper J. Fusidic acid and lincomycin therapy in staphylococcal infections in cystic fibrosis. Lancet 1970; i:9-14.

3 Weaver LT, Green MR, Nicholson K, et al. Prognosis in cystic fibrosis treated with continuous flucloxacillin from the neonatal period. Arch Dis Child 1994;70:84-9.

4 Taylor RFH, Hodson ME. Antibiotic prescribing practices in the United Kingdom and Eire. Respir Med 1993;87: 535-9.

5 Olver RE. Method and myth in the treatment of cystic fibrosis. In: Eyre J, Boyd R, eds. Paediatric speciality practice for the 1990s. London: Royal College of Physicians of London, 1991: 183-94.

6 Ramsey BW, Boat TF. Outcome measures for clinical trials in cystic fibrosis. Summary of a Cystic Fibrosis Foundation consensus conference. $\mathcal{F}$ Pediatr 1994;71:177-92.

7 Mukhopadhyay S, Singh M, Cater JI, et al. Nebulised anti-pseudomonal antibiotic therapy in cystic fibrosis: a meta-analysis of benefits and risks. Thorax 1996;51:364-8.

8 Dickersin K, Scherer R, Lefebvre C. Identifying relevant studies for systematic reviews. BMF 1994;309:1286-91.

9 Lefebvre C. The Cochrane Collaboration: the role of the UK Cochrane Centre in identifying the evidence. Health Library Review 1994;11:235-42.

10 Stutman HR, Marks MI. Cephalexin prophylaxis in newly diagnosed patients with cystic fibrosis. Sixth Annual North American Cystic Fibrosis Conference, Washington DC, 1992: 147-8.

11 Beardsmore CS, Thompson JR, Williams A, et al. Pulmonary function in infants with cystic fibrosis: the effect of antibiotic treatment. Arch Dis Child 1994;71:133-7.

12 Brown J. Efficacy of antimicrobial drugs against staphylococci in cystic fibrosis. Austral Paediatr F 1980;16:207-9.

13 Shapera RM, Matsen JM. Clindamycin therapy of staphylococcal pulmonary infections in patients with cystic fibrosis. f Pediatr 1981;99:647-50.

14 Szaff M, Hoiby N. Antibiotic treatment of staphylococcus aureus infection in cystic fibrosis. Acta Paediatr Scand 1982;71:821-6.

15 Schlesinger E, Muller W, Von der Hardt H, et al. Effect of long-term continuous anti-staphylococcal antibiotic treatment in young children with cystic fibrosis. In: Lawson D, ed. CF: horizons. Chichester: John Wiley, 1984: 280

16 Kerrebijn KF. Prospective study on the effect of daily and intermittent antibiotic treatment in cystic fibrosis. In: Lawson D, ed. CF: horizons. Chichester: John Wiley, 1984: 273.

17 Harrison CJ, Marks MI, Welch DF, et al. A multicentric comparison of related pharmacologic features of cephalexin and dicloxacillin given for two months to young children with cystic fibrosis. Pediatr Pharmacol 1985;5:7-16.

18 Jensen T, Lang S, Faber M, et al. Clinical experiences with fusidic acid in cystic fibrosis patients. I Antimicrob Chemother 1990;25(Suppl B):45-52.

19 Ballestero S, Villaverde R, Escobar H, et al. Susceptibility to various anti-microbial agents of Staphylococcus aureus isolates from cystic fibrosis patients. Eur $\mathcal{F}$ Clin Microbiol Infect Dis 1992;11:1193-4.

20 Feigelson J, Pecau Y. Action therapeutique de l'acide fusidique dans la mucoviscidose. Pediatre 1993;29/138: 111-3. 